\title{
The Extent of E-Business Usage and Perceived Cumulative Benefits: A Survey on Small and Me- dium-Sized Enterprises
}

\author{
${ }^{*}$ Rosli Mohamad ${ }^{1}$, Noor Azizi Ismail ${ }^{2}$ \\ ${ }^{1}$ School of Accountancy, Universiti Utara Malaysia, Malaysia \\ 20thman Yeop Abdullah Graduate School of Business, Universiti Utara Malaysia, Malaysia \\ *roslim@uum.edu.my
}

\begin{abstract}
Internet-based application (e-business) is well-recognized as a useful mean to extend business efficiency. Owing to the idiosyncratic nature of Small and Medium-sized Enterprises (SMEs), considerable works have been initiated to explain why firms within this sector embrace e-business. Despite extensive research to identify factors that explain the firm's e-business practice, works are still limited to examining as to what extent the e-business assimilates into business operation. Furthermore, firms would experience varying degrees of benefits by deploying e-business. Therefore, this paper reports intensity of ebusiness usage across various business processes and its relationship with cumulative benefits. A survey of 140 SMEs has revealed the diversity of e-business usage across business processes. A cluster analysis has further proposed three distinct profiles of firms based on the intensity of their e-business usage. Finally, the empirical evidence obtained has also ascertained positive association between the intensity of e-business usage and cumulative e-business benefits. Despite limitations highlighted, this paper provides evidence on the current state of e-business usage across firm operation and its likely impact to the firm operation.
\end{abstract}

Keywords: E-business diffusion, Small and medium-sized enterprises (SMEs), E-Business benefits; Malaysia

\section{Introduction}

SMEs dominate over $80 \%$ of total established businesses in most nations. In view of salient SMEs' roles in the nation's development, government and related-agencies have initiated measures to facilitate firms in extending operation productivities. Deployment of Information Technology (IT) in general and Internetbased solutions (e-business) in particular, turns out to be one of the strategic agenda to realize the government effort. More importantly, e-business is crucial for business survival in a highly knowledge-based economy as it offers vast potentials to transform various facets of business operation. Nevertheless, idiosyncratic nature of the SMEs operation would result in a different degree of reliance towards e-business. Variances of e-business usage across firms ultimately reflect unequal benefits to be realized from such investment. Responding to these arguments, this paper explores the extent of e-business deployment by the SMEs and its consequences to perceived e-business values. Specifically, the objectives of this paper are: (i) to investigate the extent to which firms perceive the Internet as a useful tool to facilitate business operation, (ii) to explore different profiles of firms based on the intensity of their e-business usage, and (iii) to assess the possible relationship between the extent of e-business usage and realized e-business benefits. This study extends the body of knowledge by providing insight as to what extent the Internet penetrates into various aspects of business functions. Earlier investigations have given particular attention on factors that potentially explain firms' decision to embrace e-business. Meanwhile, efforts to investigate how the e-business diffuses into various business functions are still limited (Elia et al., 2007; Magal et al., 2008). Investigating e-business diffusion across firm operation would offer alternative insights on creating e-business values to the firms (Cragg et al., 2007; Tallon, 2007). Close examination of e-business usage in various business functions would also facilitate identification of areas that are highly supported by e-business and the areas that deserve further investment. The authors have organized this paper into five major sections. The next section reviews the literature on IT/IS and e-business practices amongst SMEs. The third section describes research methodology employed while the results of the data analyses are reported in the fourth section. The final part presents discussions and conclusion of the study.

\section{Literature Review}

E-Business and SMEs: Commercialization of Internet in the late 1990s has transformed ways of conducting business. The Internet-based applications would facilitate firms to enhance operational efficiency, to enable global access, and to sustain competitive advantages (Poon, 2008). Issue of e-business practices 
among firms warrants further investigation as it affects firms differently than other conventional types of IT/IS. The Internet, a backbone infrastructure of e-business applications, enables wider support to the core business areas (Swanson, 1994). Specifically, the Internet act as an effective communication channel with business partners, improves information processing speed, and facilitates inter-firms collaboration (Nieto \& Fernandez, 2006). Regardless of the e-business potentials, SMEs are facing various challenges to progress with the e-business. Nature of business operation and characteristics of the SMEs differs considerably than larger firms in many aspects. The SMEs are well known for lack of innovation and unclear business strategy (Meckel et al., 2004; Schubert \& Leimstoll, 2007). The owner/manager usually has more dominant roles in promoting technology-related innovation within the firm (Lip-Sam \& Hock-Eam, 2011). In addition, SMEs face greater challenges in obtaining financial supports (Nieto \& Fernandez, 2006) and in retaining technologically competent staffs (OECD, 2004).

Reflecting vast e-business potentials in one hand and the SMEs constraints on the other, ample studies have been initiated to investigate e-business practices within this sector. Large proportions of earlier studies have concentrated on identifying drivers and barriers of e-business adoption (Mohamad \& Ismail, 2009). Most studies have measured e-business adoption using a dichotomous indicator (adopt or not adopt). Such measures, however, inadequately reflects intensity of e-business usage within firm operation (Chong, 2008). Following the need to assess intensity of e-business usage, works have started to propose various alternative measures. Among the popular approach was to measure adoption as the extent of using different e-business applications (Al-Qirim, 2007; Roberts \& Toleman, 2007). This approach enables development of various e-business adoption profiles based on the complexity of e-business as practiced by the firms (Levy et al., 2003; Magal et al., 2008). Other works had classified firms based on different stages of e-business adoption (Al-Somali et al., 2010; Molla \& Licker, 2004). In this case, a higher stage reflects more extensive use of e-business.

Alternatively, examining how the Internet diffuses into various business functions could be another insightful indication of e-business usage. E-business diffusion describes how the application of the Internet spreads into various aspects of business operation. Assessing e-business assimilation across wider aspects of business processes would portray the breadth and depth of the e-business use (Raymond et al., 2005). More importantly, not much work has explored e-business practices in SMEs from a business process standpoint and therefore warrants further consideration (Gebauer \& Shaw, 2002). Applying business process viewpoint is also crucial to understand e-business practices in SMEs (Cragg et al., 2007; Elia et al., 2007). Despite the fact that e-business potentially transforms most parts of the business operation, the SMEs do not fully embrace the e-business into their operation taking into account limited resources available for IT/IS related investment (Premkumar, 2003). Thus, greater priority would be assigned for deploying e-business applications in the business areas that are highly correspond to the strategic business objectives of the firms (Bharati \& Chaudhury, 2006). In a similar vein, the e-business usage is more pervasive to support the primary business functions rather than the secondary business functions of the firms (Koh \& Nam, 2005; Magal et al., 2008). Firms may also prioritize e-business investment based on their focused business processes (Elia et al., 2007). In another respect, firms follow an evolutionary process by deploying Internet to support least complicated functions and gradually progresses into more complex functions (Wilson et al., 2008).

Realized E-business Benefits: Firms employ e-business mainly to improve productivity and operational efficiency. In view of limited resources and capabilities, many SMEs experience unsatisfactory benefits from their e-business investment (Ong \& Lin, 2011). Hence, assessment of e-business impacts becomes one of the key issues among IT/IS researchers (Koo et al., 2007). In the early days, deployment of standalone computerized applications merely affects specific business function (Straub et al., 2002). In contrast, the Internet that allows broader connectivity (Zhu \& Kraemer, 2005) impinges the entire span of the business functions. Therefore, the Internet would expand firm's market share, establish an effective inter-firms interaction, and promote faster information exchange. The Internet-based applications also foster more effective customer service, communication among employees, as well as coordination with business partners (Zhu et al., 2004). Having considered that, the e-business promises positive impacts to firm performance, particularly to their core business functions; sales-related, internal operation, and procurement-related (Zhu \& Kraemer, 2005). Nonetheless, the studies on e-business impacts are limited despite constant calls to understand the phenomena (Eriksson et al., 2008). In brief, the central premise of this paper is that firms with more widespread deployment of e-business would derive greater levels of benefits from their e-business investment. 


\section{Methodology}

This study employed a mail survey procedure to accumulate empirical evidence on intensity of e-business usage by Malaysian SMEs. Profiles of 1,430 sample firms were obtained from SME Corporation (Malaysia) directory. Self-administered questionnaire was then mailed to the owner/manager of the respective firm. The questionnaire consists of four parts. The first part identifies selected firms' profiles. The second part assesses intensity of e-business usage on 36 business activities. The items were shortlisted from earlier work on similar context (Bharati \& Chaudhury, 2006; Elia et al., 2007). This part conceptualizes intensity of e-business usage as the firm's perceived importance of the Internet to support each of the business activities. The third part solicits respondent's perception on realized impacts of e-business to the firm with respect to commerce, coordination, and productivity (Kraemer et al., 2002). The last part collects information about the respondent's profile. Both constructs were measured using a 5-point scale.

Although 155 firms had responded to the survey, only 140 responses were found valid for further analysis (9\% response rate). The non-response bias test based on extrapolation approach (Armstrong \& Overton, 1977) revealed minimal presence of a response bias problem. Overall, there is a relatively equal proportion between small firm and medium-sized firm. With respect to firm age, about two-third were classified as matured firms (over 10 years in operation). Meanwhile, manufacturing-based firms (67\%) dominated the survey in relative to service-based firms (33\%). In terms of exporting activities, about $30 \%$ of the firms did not generate revenue from exporting activities while slightly less than half of the firms reported less than $50 \%$ of export activities.

\section{Results}

Generally, the descriptive analysis shows the diversity of Internet support across 36 business processes being examined. Firms extensively deployed the Internet to support 'information searching', 'information communication', 'advertising', 'customer seeking', and 'customer services' activities. In contrast, respondents denoted least Internet supports for 'delivery/receipt of products', 'tracking of purchase/delivery', 'purchasing of non-inventory items', and 'making/receiving payments online' activities. In addition, uses of the Internet in finance-related tasks such as 'communication with shareholders' and 'reporting financial results' were reported as substantially low.

Diversity of e-business usage across business functions would raise a concern whether firms could be classified into several meaningful profiles depending on how e-business supports their operation. Therefore, the next attempt is to group firms with similar e-business usage patterns. This paper employed a cluster analysis technique for the profiling purposes. The cluster analysis is appropriate in classifying cases (firms) based on the predefined variables (Hair et al., 2010). This study had considered rating scores on perceived Internet support as the clustering variables. For simplification, a principal component analysis was first executed to unveil underlying components representing the 36 business processes items. The results identified five components with 32 items were retained. The components were labeled as 'sales and sales-related' (13 items), 'procurement-related' (8 items), 'in-house operation' (4 items), 'information searching' (4 items), and 'financial-related' (3 items). Using the hierarchical clustering technique, the results proposed three groups to represent the sample firms with 33,62 , and 45 firms were classified in each respective group. Significant ANOVA results for all aspects of e-business usage and post-hoc tests have ascertained validity of the clustering results (Table 1).

TABLE1. Mean of Internet Support by Clusters

\begin{tabular}{lcccccl}
\hline & $\begin{array}{c}\text { Cluster 1 } \\
(\mathbf{n = 3 3 )}\end{array}$ & $\begin{array}{c}\text { Cluster 2 } \\
(\mathbf{n = 6 2 )}\end{array}$ & $\begin{array}{c}\text { Cluster 3 } \\
(\mathbf{n = 4 5 )}\end{array}$ & $\begin{array}{c}\text { Combined } \\
(\mathbf{N = 1 4 0 )}\end{array}$ & F-value & \\
\hline Sales and sales related & 2.24 & 3.06 & 3.97 & 3.16 & 93.12 & $*$ \\
Procurement-related & 1.84 & 2.58 & 3.51 & 2.71 & 102.34 & $*$ \\
Financial related & 1.35 & 2.52 & 3.20 & 2.46 & 48.01 & $*$ \\
Information searching & 2.94 & 3.39 & 4.30 & 3.58 & 33.79 & $*$ \\
In-house operation & 1.71 & 3.01 & 4.09 & 3.05 & 116.97 & $*$ \\
\hline
\end{tabular}

*Significant at 99\% confidence level 
Figure 1 further compares the mean-centered values (the difference between a cluster mean score and overall mean score) across the groups. The comparison facilitates researchers to examine e-business usage patterns and distinct characteristics of each group.

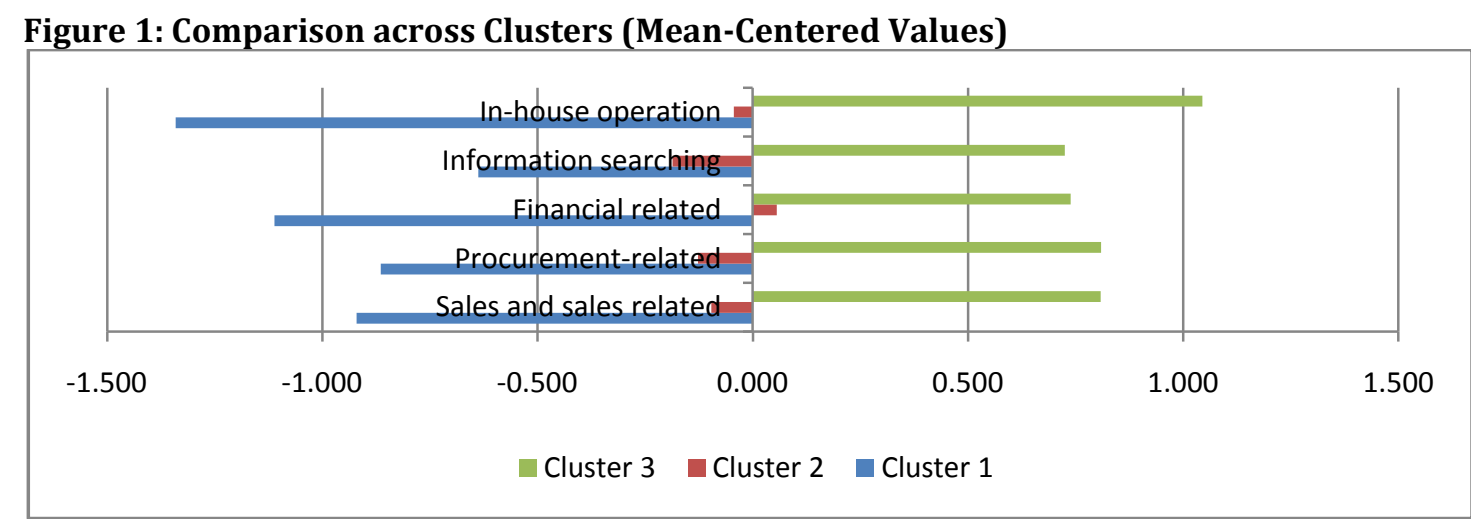

The following paragraphs elaborate the characteristics and suggest the appropriate label representing each of the identified clusters.

Cluster 1- Restricted Adopters: The results show minimal use of e-business applications among firms in this cluster. Overall, firms perceived relatively far lower than average of e-business support in relative to other clusters. However, as Figure 1 indicates, the gap across clusters was somewhat lower for basic Internet activities such as 'information searching'. This would suggest that firm's use of e-business applications is quite extensive for searching business-related information and for information communication purposes. Meanwhile, the use of advanced e-business features was limited among firms in this group.

Cluster 2 - Modest Adopters: Firms classified in his group generally have a moderate intensity of Internet usage in all business processes. This is supported by the fact that firms have reported slightly below than average scores for most aspects of e-business usage. However, as Figure 1 reveals, firms moderately used the Internet for 'sales and sales-related', 'information searching', and 'in-house related' activities.

Cluster 3 - All-embracing Adopters: As the results portray, firms in cluster 3 comparatively reported above average mean scores in all business areas. However, the most extensive use of the Internet was mainly for 'in-house operation' and 'sales and sales-related' activities'. Additionally, the results further suggest that firms had integrated various e-business sophistications across business operation ranging from communication, information searching, and transaction-related activities.

In response to the three profiles identified, the final objective of this paper is to explore possible links between intensity of e-business use and cumulative e-business benefits. This paper anticipates that greater e-business benefits are to be realized mainly by firms with more extensive e-business usage. A Kruskal Wallis test was employed to compare perceived e-business impacts across the three profiles. The mean rank and F-value for each measure is reported in Table 2. Significant chi-square values for all 10 measures of perceived benefits suggest significant differences of the mean ranks across the clusters. Moreover, 'All-embracing adopters' group has reported the highest mean ranks in all aspects of e-business impact examined, followed by 'Modest adopters' group and 'Restricted adopters' group. Therefore, it is appropriate to suggest that firms with extensive e-business deployment across various business processes tend to realize greater e-business benefits.

Table 2: Mean Rank of Perceived E-business Benefits by Profiles

\begin{tabular}{lcccccc}
\hline E-business benefits & \multicolumn{4}{c}{ Mean Rank } & Chi-square \\
\cline { 2 - 5 } & $\begin{array}{c}\text { Restricted } \\
\text { adopters }\end{array}$ & $\begin{array}{c}\text { Modest adop- } \\
\text { ters }\end{array}$ & $\begin{array}{c}\text { All-embracing } \\
\text { adopters }\end{array}$ & Chi-s \\
\hline Commerce & 56.02 & 64.69 & 89.12 & 16.569 & $*$ \\
Widen the sales area & 52.15 & 67.74 & 87.76 & 16.436 & $*$ \\
Domestic sales & 57.53 & 61.55 & 92.34 & 20.875 & $*$ \\
International sales & 45.2 & 65.61 & 95.79 & 34.933 & $*$ \\
Competitiveness & 16 & & & &
\end{tabular}


Table 2: Mean Rank of Perceived E-business Benefits by Profiles (cont.)

\begin{tabular}{lccccc}
\hline \multirow{2}{*}{ E-business benefits } & \multicolumn{3}{c}{ Mean Rank } & \multirow{2}{*}{ Chi-square } \\
\cline { 2 - 5 } & $\begin{array}{c}\text { Restricted } \\
\text { adopters }\end{array}$ & $\begin{array}{c}\text { Modest } \\
\text { adopters }\end{array}$ & $\begin{array}{c}\text { All- } \\
\text { embracing }\end{array}$ & & \\
\hline Customer service & 50.26 & 60.9 & 98.58 & 37.460 & $*$ \\
Coordination & & & & & \\
Procurement cost & 56.89 & 59.93 & 95.04 & 26.457 & $*$ \\
Inventory cost & 56.94 & 60.75 & 93.88 & 23.701 & $*$ \\
Coordination with supplier & 57.15 & 61.01 & 93.37 & 23.074 & $*$ \\
Productivity & & & & & \\
Internal processes & 50.29 & 59.43 & 100.58 & 41.388 & $*$ \\
Employee productivity & 51.65 & 58.9 & 100.3 & 39.777 & $*$ \\
\hline
\end{tabular}

*Significant at 99\% confidence level

\section{Conclusion}

The Internet offers great opportunities as well as challenges for firms of all sizes to transform their business operation. Instead of examining types of e-business technologies being deployed, this paper investigates the extent of Internet support across various business processes and its impacts to business operation. In the context of SMEs, the results have demonstrated that firms extensively employed e-business for 'information searching', 'information communication', and 'customer-related services'. This corresponds to the prediction that customer-oriented firms put greater priority over functions that have the potential to extend relationships with their customers (Tallon, 2007). Therefore, these functions would receive greater priority when firms consider e-business as a tool to enhance business efficiency. Apart from the firm's strategic focus, extensive use of e-business to support these activities could be due to the activities are easily transformed into 'online' as compared to transaction-related activities (Koh \& Nam, 2005). Meanwhile, the results have revealed limited e-business deployment for transaction-related tasks such as 'order processes', 'payment processes', and 'order tracking.' Technically, these functions demand for more sophisticated and expensive IT infrastructure. Thus, taking into consideration financial constraints, not many SMEs have yet to consider such capabilities. Nevertheless, limited use of e-business to support transaction processing activities complement to the trends reported in other developing economies (Spremic, 2007). Results based on business process components have also revealed the limited use of the Internet to support procurement-related tasks. The expensive cost of deploying an e-procurement system could justify low penetration of the Internet in this business function. Although the initial intention of introducing an e-procurement system is to enhance business efficiency and to minimize cost of securing resources, SMEs still perceive e-procurement system as infeasible to their business (Eei et al., 2012).

The study further classifies firms into three distinct groups based on intensity of e-business usage across business processes. The most obvious difference across the groups is on their overall intensity of ebusiness. 'All-embracing adopters' have extensively deployed e-business in all aspects of their business operation. In contrast, firms classified as 'Restricted adopters' perceive limited Internet support to their business. However, this study unable to reveal profiles with distinct e-business focus as reported in earlier studies (Elia et al., 2007; Wilson et al., 2008). Despite the limitation, the results would suggest that firms probably put different priority in Internet-related investment. The findings to some extent explain firms' tendency to invest in e-business applications that highly correspond to their strategic business needs.

The results have also confirmed a positive association between intensity of e-business deployment and the cumulative e-business values. This is in line with the earlier study's suggestion that firms with more extensive e-business usage tend to experience greater benefits out of their investment (Elia et al., 2007; Schubert \& Leimstoll, 2007). Such pattern might not happen at random but could be due to an evolutionary learning process that shapes the development of e-business uptakes within the firms (Elia et al., 2007). The learning process and experience of deploying e-business applications gradually develop firm's confidence and trust towards the e-business capabilities. In turn, firms are more likely to embrace more sophisticated e-business applications or widen the scope of e-business usage across business operations. 
The findings trigger next key concern on e-business practices in SMEs. It is interesting to explore further how intensity of e-business usage is in alignment with their strategic business functions. This is an urgent issue as firm's ability to align e-business capability with their most critical functions creates greater IT/ISrelated investment value (Cragg et al., 2007). The outcome would extend the findings of the present study by locating areas of business that deserve further e-business investment.

Finally, readers should interpret the results with caution taking into consideration several limitations of the present study. First, the sample size is relatively small. Regardless of the various efforts that have been taken to increase the responses to the survey, the response rate remains low. Therefore, readers should not directly infer the findings to the SMEs at large. Secondly, like most of other similar studies, this study has measured the intensity of e-business usage and perceived e-business benefits in a subjective manner. Although the use of subjective measure is acceptable (Cragg et al., 2007; Tallon, 2007), the use of more objective measures would help to alleviate the perception bias.

Acknowledgment: We would like to thank the Ministry of Higher Education of Malaysia (MOHE) and Universiti Utara Malaysia (UUM) for funding this research.

\section{References}

Al-Qirim, N. A. (2007). The adoption of ecommerce communications and application technologies in small businesses in New Zealand. Electronic Commerce Research and Applications, 6(4), 462 - 473.

Al-Somali, S., Gholami, R. \& Clegg, B. (2010). An Investigation into the adoption of electronic business in Saudi Arabia using the Technology-Organization-Environment Framework. UK Academy for Information Systems Conference Proceedings 2010. Paper 6. Retrieved from http://aisel.aisnet.org/ukais2010/6

Armstrong, J. S. \& Overton, T. S. (1977). Estimating non-response bias in mail surveys. Journal of Marketing Research, 14, 396-402.

Bharati, P. \& Chaudhury, A. (2006). Studying the current status of technology adoption. Communications of the ACM, 49(10), 88 - 93.

Chong, S. (2008). Success in electronic commerce implementation: A cross -country of small and mediumsized enterprises. Journal of Enterprise Information Management, 21(5), 468 - 492.

Cragg, P. B., Tagliavini, M. \& Mills, A. (2007). Evaluating the alignment of IT with business processes in SMEs. 18th Australasian Conference on Information Systems. Toowoomba, Australia.

Eei, K. S., Husain, W. \& Mustaffa, N. (2012). Survey on the benefits and barriers of e-procurement: Malaysian SMEs perspective. International Journal on Advanced Science, Engineering and Information Technology, 2(6), $14-19$.

Elia, E., Lefebvre, L. A. \& Lefebvre, É. (2007). Focus of B-to-B e-commerce initiatives and related benefits in manufacturing small-and medium-sized enterprises. Information Systems and ebusiness Management (ISeB), 5(1), 1 - 23.

Eriksson, L. T., Hultman, J. \& Naldi, L. (2008). Small business e-commerce development in Sweden - an empirical survey. Journal of Small Business and Enterprise Development, 15(3), 555 - 570.

Gebauer, J. \& Shaw, M. J. (2002). Introduction to the special section: Business-to-Business electronic commerce. International Journal of Electronic Commerce, 6(4), 7-17.

Hair, J. F., Black, W. C., Babin, B. J. \& Anderson, R. E. (2010). Multivariate data analysis. New Jersey, USA: Pearson Prentice Hall.

Koh, C. E. \& Nam, K. T. (2005). Business use of the Internet: A longitudinal study from a value chain perspective. Industrial Management \& Data Systems, 105(1), 82 -95.

Koo, C., Song, J., Kim, Y. J. \& Nam, K. (2007). Do e-business strategies matter? The antecedents and relationship with firm performance. Information Systems Frontiers, 9(2-3), 283 - 296.

Kraemer, K. L., Gibbs, J. \& Dedrick, J. (2002). Impacts of globalization on e-commerce adoption and firm performance: A cross-country investigation. University of California. Irvine: Center for Research on Information Technology and Organizations.

Levy, M., Powell, P. \& Yetton, P. (2003, June). IS alignment in small firms: New paths through the maze? Paper presented at 11th European Conference on Information Systems. Naples, Italy.

Lip-Sam, T. \& Hock-Eam, L. (2011). Estimating the determinants of B2B e-commerce adoption among small and medium-sized enterprises. International Journal of Business and Society, 12(1), 15 - 30.

Magal, S. R., Koslage, P. \& Levenburg, N. M. (2008). Towards a stage model for e-business adoption among SMEs: Preliminary results for manufacturing and service firms. Fourteenth America's Conference on Information Systems. Toronto, Canada: 14 - 17 August. 
Meckel, M., Walters, D., Greenwood, A. \& Baugh, P. (2004). Taxonomy of e-business adoption and strategies in small and medium sized enterprises. Strategic Change, 13(5), 259 - 269.

Mohamad, R. \& Ismail, N. A. (2009). Electronic commerce adoption in SME: The trend of prior studies. Journal of Internet Banking and Commerce, 4(1), 1 - 14.

Molla, A. \& Licker, P. S. (2004). Maturation stage of ecommerce in developing countries: A survey of South African companies. Information Technologies and International Development, 1(3), 89 - 98.

Nieto, M. J. \& Fernandez, Z. (2006). The role of information technology in corporate strategy of small and medium enterprises. Journal of International Entrepreneur, 3, 251 - 262.

Organization for Economic Co-operation Development [OECD]. (2004). ICT, E-Business and SMEs. Paris, France: OECD Publication Services.

Ong, C. S. \& Lin, C. T. (2011). Creating e-business value and firm performance from supply chain perspective.15th Pacific Asia Conference on Information Systems (PACIS) 2011 (pp. 1 - 14). Brisbane, Australia: Association for Information Systems.

Poon, S. (2008). Future of small business e-commerce. In A. Becker (Ed.), In Electronic commerce concepts, methodologies, tools and applications, IV, 1466 - 1473. Information Science Reference.

Premkumar, G. (2003). A meta-analysis of research on information technology implementation in small business. Journal of Organizational Computing and Electronic Commerce, 13(2), 91 - 121.

Raymond, L., Bergeron, F. \& Blili, S. (2005). The assimilation of e-business in manufacturing SMEs: Determinants and effects on growth and internationalization. Electronic Markets, 15(2), 106 -118.

Roberts, B. \& Toleman, M. (2007). One-size e-business adoption model does not fit all. Journal of Theoretical and Applied Electronic Commerce Research, 2(3), 49 - 61.

Schubert, P. \& Leimstoll, U. (2007). Importance and use of information technology in small and mediumsized companies. Electronic Markets, 17(1), 38 - 55.

Spremic, M. A. (2007). Development of e-commerce in Croatia: A survey. Information Technology for Development, 13(4), 391-409.

Straub, D., Hoffman, B., Weber, C. \& Steinfield, C. (2002). Toward new metrics for net-enhanced organizations. Information Systems Research, 13(3), 227 - 238.

Swanson, E. B. (1994). Information systems innovation among organization. Management Science, 40(9), $1069-1092$.

Tallon, P. P. (2007). A process-oriented perspective on the alignment of information technology and business strategy. Journal of Management Information Systems, 24(3), 227-268.

Wilson, H., Daniel, E. \& Davies, I. A. (2008). The diffusion of e-commerce in UK SMEs. Journal of Marketing Management, 24(5/6), 489 - 516.

Zhu, K. \& Kraemer, K. L. (2005). Post-adoption variations in usage and value of e-business by organizations: Cross-country evidence from the retail industry. Information Systems Research, 16(1), 61 84.

Zhu, K., Kraemer, K. L., Xu, S. \& Dedrick, J. (2004). Information technology payoff in e-business environments: An international perspective on value creation of e-business in the financial service industry. Journal of Management Information Systems, 21(1), 17-54. 